\title{
Crossed complete fused left to right renal ectopia with solitary left ureter: A rare 'Case Report'
}

Ghanshyam Kumawat ${ }^{1,2^{*}}$, Mohit Singla ${ }^{1}$, Nishkarsh Mehta ${ }^{1}$, Prashant Gupta ${ }^{1}$ and SS Yadav ${ }^{1}$

\begin{abstract}
Background: Crossed fused renal ectopia is a rare congenital anomaly where both the kidneys are fused and situated on one side and drain bilaterally into the urinary bladder. Rarely crossed fused ectopia can present with a single ureter draining ipsilaterally into the bladder, but here we are presenting for the first time a rare case of right crossed fused ectopia, where a solitary ureter crosses midline and drains contralaterally into the bladder.
\end{abstract}

Case presentation: A 19-year-old adolescent male patient presented with intermittent chronic right flank pain for 3 months. General physical and per abdominal examinations were normal. Computerized tomography (CT) urography showed right side crossed fused ectopic kidneys with a solitary ureter draining both the kidneys and opening into the left side of the urinary bladder. The patient was managed conservatively and is on regular follow-up.

Conclusion: Crossed complete renal fused ectopia with solitary contralateral ureteral is a rare case. Individualized case-based management is needed depending upon the symptoms, associated anomalies, and pathology. Reporting of all rare congenital cases will help in the future understanding and management of these conditions.

Keywords: Crossed fused ectopia, Solitary ureter, CT urography, Case report

\section{Background}

Crossed fused renal ectopia is a rare congenital anomaly where both the kidneys lie on one side of the body, usually with two pelvis and ureters draining bilaterally into the urinary bladder. It is diagnosed incidentally or due to flank pain, dysuria, hematuria, or fever secondary to obstruction of the pelvicalyceal system. In the literature, we have found seven reported cases of crossed fused ectopia with a single ureter draining ipsilaterally into the bladder. We came across a peculiar case of crossed fused ectopia of right side with solitary ureter crossing midline and draining into the left side of the bladder. This is probably being reported for the first time.

\footnotetext{
*Correspondence: Drgskumawat025@gmail.com

${ }^{2}$ Village Chhapoli, Near Old Bus Stand, Tehsil Udaipurwati, Dist

Jhunjhunu, Rajasthan 333302, India

Full list of author information is available at the end of the article
}

\section{Case presentation}

A 19-year-old male patient came to our outpatient department (OPD) with right flank pain for the last 3 months, pain was intermittent, dull aching, non-radiating, no aggravating factors and the severity of pain was mild, which was not affecting daily routine activities of the patient, and he was not on any treatment for the pain. There was no history of any other gastrointestinal or genitourinary complaints, and the patient's past and family history was not significant. General physical and systemic examinations were normal. Routine blood and urine investigations were within normal limits. Ultrasonography (USG) suggested the absence of the left kidney in the left renal fossa and fused kidneys present in the right renal fossa (Fig. 1). Contrast-enhanced computerized tomography (CECT) abdomen with urography suggested right side crossed fused ectopic kidneys with a solitary ureter draining both kidneys and opening into the left side of the urinary bladder along 


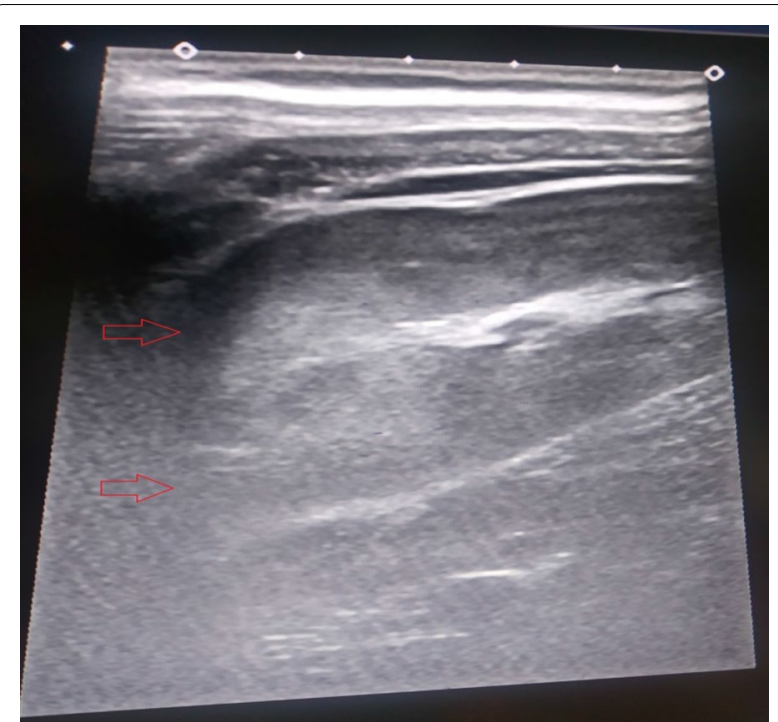

Fig. 1 USG film of the patient showing crossed fused ectopia

with a simple cyst of $8 \times 7 \mathrm{~cm}$ at the upper pole of the right kidney and $3 \mathrm{~mm}$ right renal calculus (Figs. 2, 3 and 4). The patient was managed conservatively and discharge after symptomatic improvement with advice to follow-up routinely. He is doing well in follow-up and still asymptomatic even after 1 year.

\section{Discussion}

In crossed fused renal ectopia, both the kidneys are fused and situated on one side of the body. It is a rare congenital anomaly with an incidence of approximately 1:1300 to 1:7500 [1]. Although the exact incidence is difficult to be estimated, as it does not cause symptoms in most of the patients. Males are more commonly affected, and mostly ectopic left kidney crosses to the right side of the abdomen [2].

McDonald and McClellan classified crossed fused renal ectopia into six types based upon orientation of fused kidney and ureter $[3,4]$ (Fig. 5). In descending order of occurrence, they are:

Unilateral fused kidney inferior ectopic where the lower pole of orthotopic kidney fuses with the upper pole of the crossed ectopic kidney.

Sigmoid or S-shaped kidney where normal side kidney is present superiorly and the direction of pelvic is medial, the kidney which crosses positioned inferiorly with direction of pelvic toward the lateral side. As kidneys fuse after complete rotation on the vertical axis, both renal pelves lie in correct orientation.

Unilateral lump kidney where fusion occurs over a wide margin, both renal pelves anteriorly directed and placed more inferiorly.

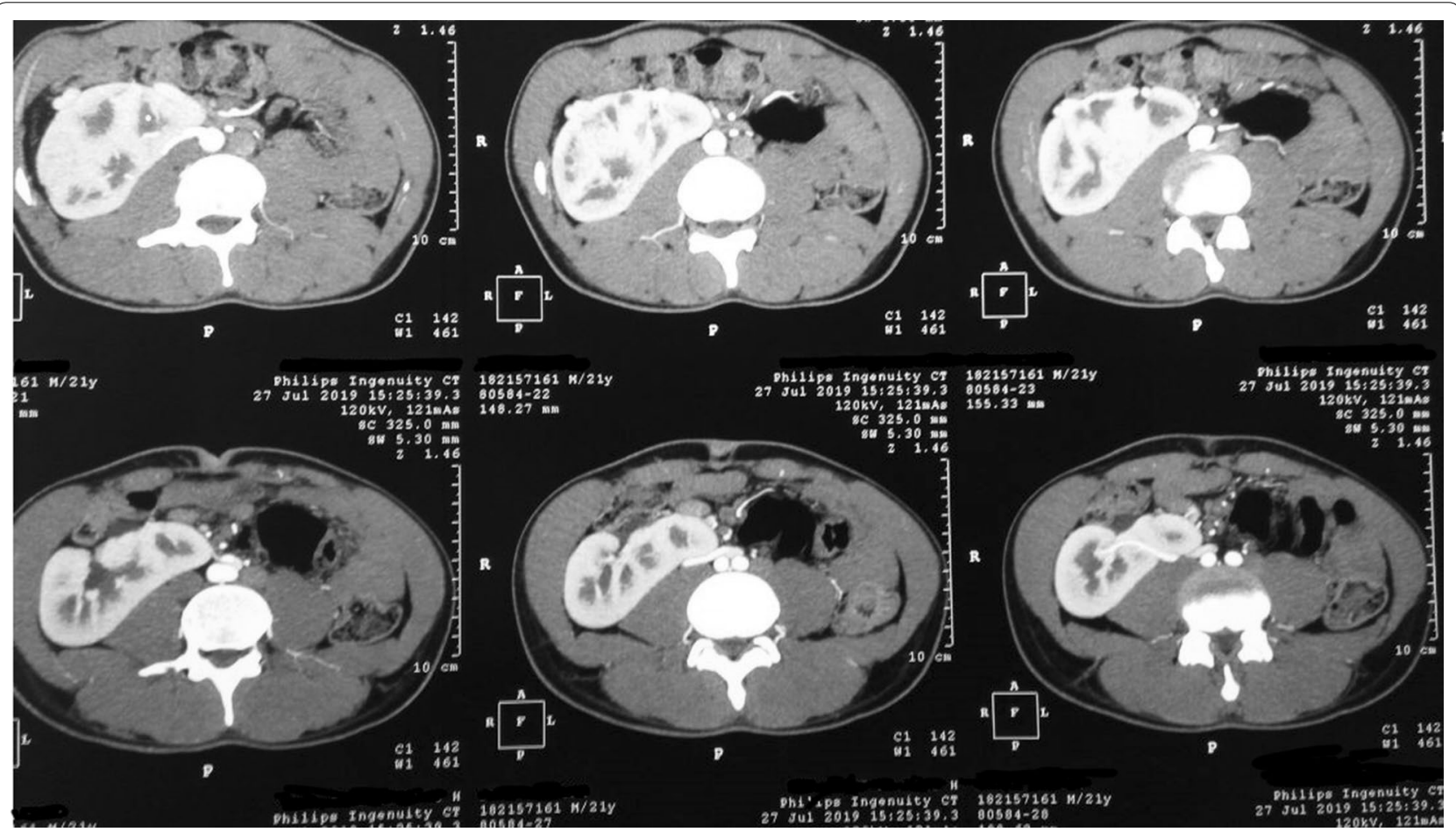

Fig. 2 CECT abdomen film of the patient showing crossed fused ectopia 


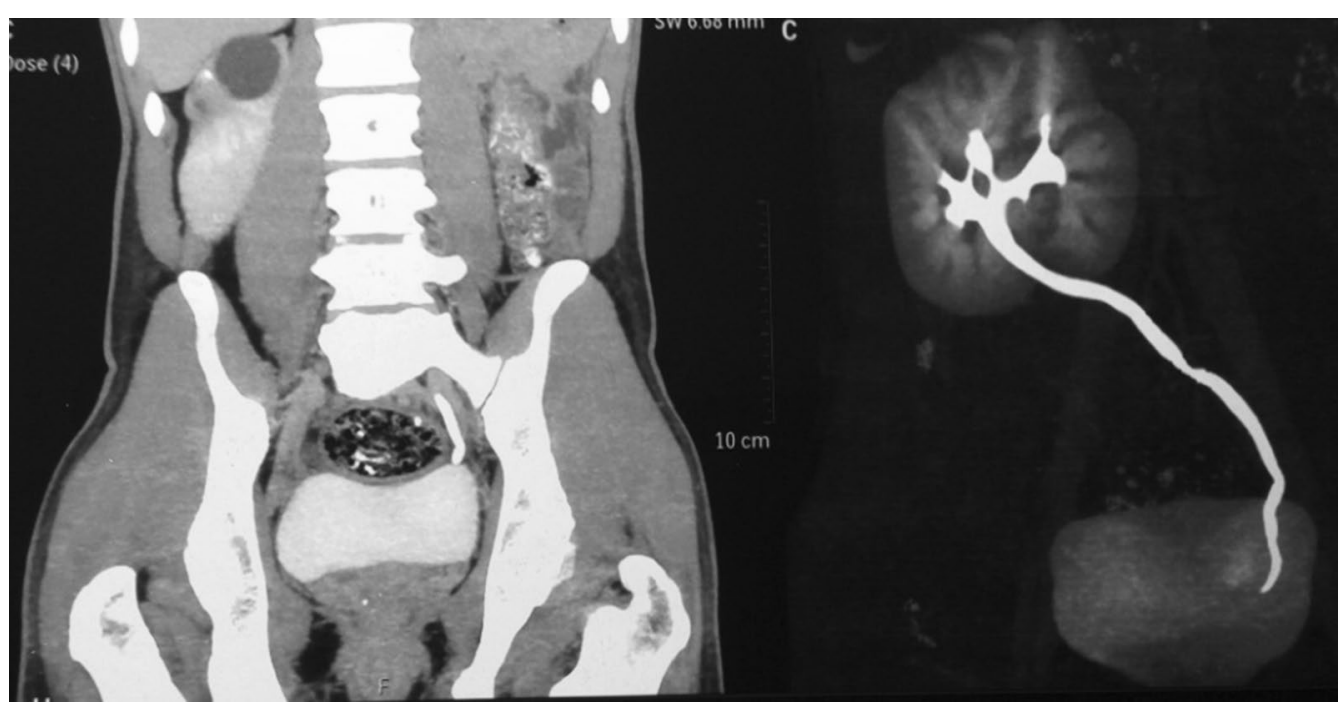

Fig. 3 CT Urography film of patient showing crossed fused ectopia

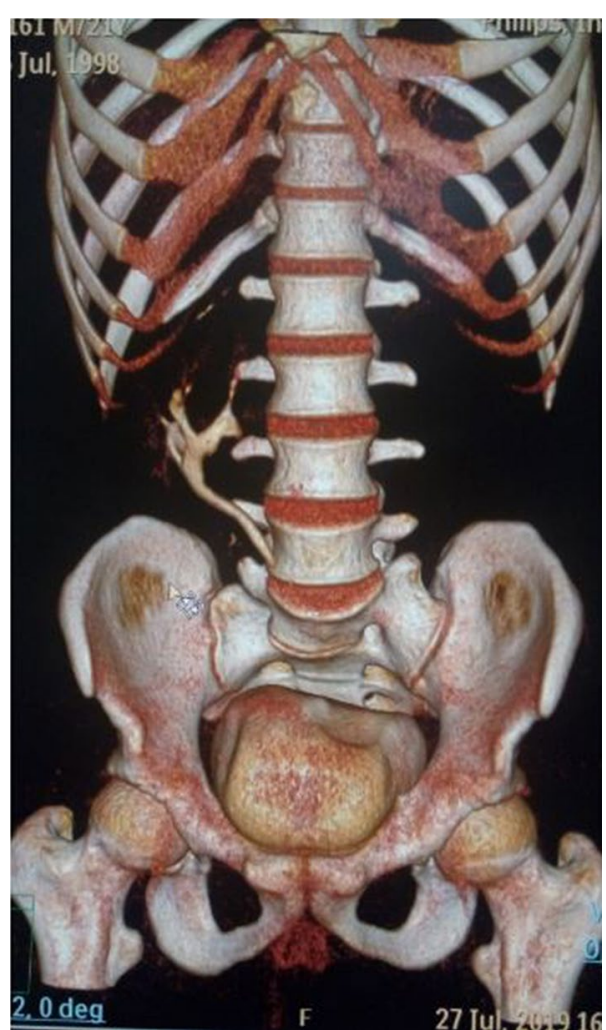

Fig. $43 \mathrm{D}$ reconstructed $\mathrm{CT}$ urography of patient

L-Shaped or tandem kidney in which the crossed kidney lies inferiorly and transversely, fused with the lower pole of the normal kidney.

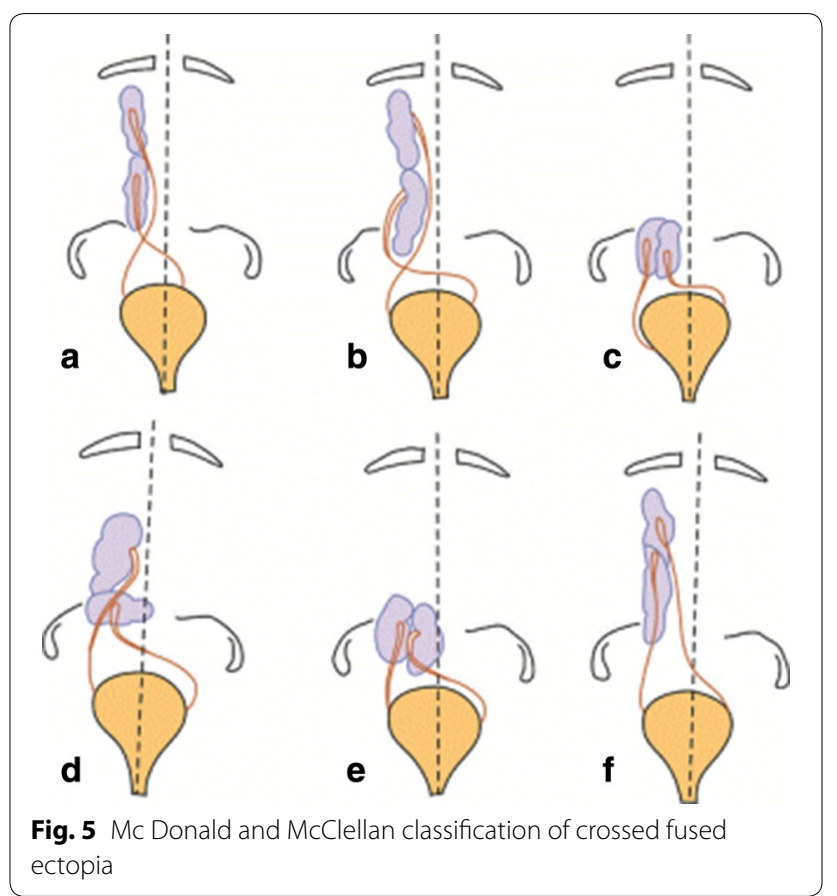

Unilateral disk kidney in which kidneys fuse along medial borders and

Unilateral fused kidney superior ectopia, the ectopic kidney lies superiorly and its lower pole fuses with the upper pole of the normal kidney. The renal pelvis of both kidneys lies anteriorly.

As per the above classification, corresponding ureters of these kidneys drain down orthotopically into 
the bladder. In the majority of the patients, diagnosis is almost an incidental finding, but 30\% of these patients present with on and off flank pain, dysuria, hematuria, and fever due to obstruction or infection [5]. Pelviureteric junction obstruction, hydronephrosis, and nephrolithiasis may be associated with this condition [6]. Other associated anomalies are imperforate anus (4\%), skeletal deformities (4\%), and cardiovascular septal anomalies [7].

USG is a good modality to demonstrate the presence of fused renal ectopia. The sonographic findings usually suggest an absent kidney in the contralateral renal fossa or pelvis and fused kidneys on the ipsilateral side. Contrast-enhanced CT with delayed film is useful for better appreciation of vascular supply, anatomy of draining ureter which is required for proper surgical management. If there are no associated anomalies and complications, then the prognosis of the crossed fused renal ectopia is very good [8].

The exact embryological basis of crossed fused renal ectopia has not been clearly understood till date. Normally, kidney develops from the ureteric bud and the metanephric blastema. The ureteric bud originates from the Wolffian duct, and the metanephric blastema is mesodermal in origin; both of them grow toward each and fuse to form kidney and pelvicalyceal system. The most commonly accepted theories of the development of crossed fused ectopia are ureteral theory and mechanical theory [2]. According to ureteric theory, it is assumed that excessive bending along with embryonal caudal end rotation prevents fusion of the ipsilateral metanephric blastema and ureteric bud and it turns toward the opposite side. Because of the stimulation of the mesonephric blastema twice by normal migrated ureteric bud, two kidneys are formed on one side [2,9]. According to mechanical theory, an abnormally positioned umbilical artery is responsible for the abnormal ascent of the developing kidney, which migrates toward the opposite side due to the least resistance in the pathway $[2,4]$.

However, this theory does not fit in our case as there was solitary ureter for both kidneys which was draining in opposite side of ectopia. So embryology of ectopia needs to be re-evaluated.

\section{Conclusion}

Complete crossed fused right-to-left ectopia with the left solitary ureter is rare case. It can be associated with other anomalies such as renal cyst and stone disease, but only conservative management and follow-up may be sufficient when the stone is small and the cyst is simple. Reporting of such cases will guide in future the understanding and management of these anomalies.

\section{Abbreviations}

CECT: Contrast-Enhanced Computerized Tomography; USG: ultrasonography; OPD: Outpatient Department.

\section{Acknowledgements \\ None.}

\section{Author's contribution}

Idea and core concept of Project was given by SS. Collection and interpretation of the data was done by GS and NM and MS. All authors were involved in writing and editing case report. Case report was supervised and finally reviewed by: SS and PG. All authors have read the manuscript and gave approval before final submission to African Journal of Urology.

\section{Funding}

None.

Availability of data and material

All data which were presented in case report are with corresponding author and will be provided on demand by journal.

\section{Competing interest}

There were no conflicts of interest.

\section{Consent for publication}

Taken from participant in written, and it was informed.

\section{Ethic approval and consent for participate}

Taken from patient, and as our institute protocol, we do not require ethics committee clearance for publication of case report.

\section{Author details \\ ${ }^{1}$ Department of Urology, SMS, Medical College, Jaipur, India. ${ }^{2}$ Village Chhapoli, Near Old Bus Stand, Tehsil Udaipurwati, Dist Jhunjhunu, Rajasthan 333302 , India.}

Received: 7 July 2020 Accepted: 12 October 2020

Published online: 24 November 2020

\section{References}

1. Türkvatan A, Olçer T, Cumhur T (2009) Multidetector CT urography of renal fusion anomalies. Diagn Interv Radiol 15:127-134

2. Loganathan A, Bal H (2019) Crossed fused renal ectopia in children: a review of clinical profile, surgical challenges, and outcome. J Pediatr Urol 15(4):315-321

3. Mcdonald JH, Mcclellan DS (1957) Crossed renal ectopia. Am J Surg 93(6):995-1002

4. Babu C, Sharma V, Gupta O (2015) Renal fusion anomalies: a review of surgical anatomy. Anat Physiol 5:s5

5. Saha S, Mriglani R, Saini P, Gupta A, Kaur N (2013) Crossed fused renal ectopia with a single ureter: a rare anomaly. Saudi J Kidney Dis Transplant 24(4):773

6. Larré S, Carpentier X, Sèbe P, Tassart M, Cussenot O, Traxer O (2007) A report of unusual crossed fused renal ectopia and minimal invasive management of calculi. Surg Radiol Anat 29(5):393-395

7. Wein AJ, Kavoussi LR, Novick AC, Partin AW, Peterseds CA, Bauer SB (2007) Anomalies of the upper urinary tract. Saunders-Elsevier, Philadelphia

8. Akdogan L, Oguz A, Ergun T, Ergun I (2015) The rarest of the rare: crossed fused renal ectopia of the superior ectopia type. Case Rep Nephrol 2015:1-4

9. CookWA, Stephens FD (1977) Fused kidneys: morphologic study and theory of embryogenesis. Birth Defects Orig Artic Ser 13:327-340

\section{Publisher's Note}

Springer Nature remains neutral with regard to jurisdictional claims in published maps and institutional affiliations. 